\title{
Community-based Norms About Intimate Partner Violence: Putting Attributions of Fault and Responsibility into Context
}

\author{
Catherine A. Taylor • Susan B. Sorenson
}

Published online: 12 September 2007

(C) Springer Science + Business Media, LLC 2007

In the text on page 577 of the online publication and the printed publication of "Community-based Norms About Intimate Partner Violence: Putting Attributions of Fault and Responsibility into Context" (Volume 53, October 2005, pp. 573-589, DOI: 10.1007/s11199-005-7143-7) a typesetting error was made in production. The text next to the first bullet under number one is incorrect. It should read as follows:

- Four response options were read to the respondent: mostly [assailant's name], mostly [victim's name], both are equally at fault, or neither is at fault.

Springer regrets the error.

The online version of the original article can be found at http://dx.doi. org/10.1007/s11199-005-7143-7.

C. A. Taylor $(\bowtie)$

Columbia University, School of Social Work,

New York, NY, USA

e-mail: cat28@cornell.edu

C. A. Taylor · S. B. Sorenson

Department of Community Health Sciences,

UCLA School of Public Health,

Los Angeles, CA, USA

C. A. Taylor

Tulane School of Public Health \& Tropical Medicine,

1440 Canal Street,

New Orleans, LA 70112, USA 